This is a non-peer reviewed preprint submitted to EarthArXiv, which is now under review at Nature Geoscience.

1 Northern peatland depth and lateral expansion is inconsistent with a 1055 GtC estimate

\title{
of carbon storage
}

\section{Joshua L. Ratcliffe ${ }^{1^{*}}$, Haijung Peng ${ }^{2^{*}}$, Jelmer J. Nijp ${ }^{3}$, Mats B.Nilsson ${ }^{1}$}

${ }^{1}$ Department of Forest Ecology and Management, Swedish University of Agricultural Sciences, Umeå, Sweden

${ }^{2}$ State Key Laboratory of Environmental Geochemistry, Institute of Geochemistry, Chinese Academy of Sciences, 550081, Guiyang, China

${ }^{3}$ Ecohydrology Department, KWR Watercycle Research Institute, Nieuwegein, The Netherlands

*Authors for correspondence: joss.ratcliffe@slu.se, haijun.peng@slu.se

\section{Introductory Paragraph}

Peatlands contain one of the largest stores of terrestrial carbon and exert a considerable influence on the global climate cycle ${ }^{1}$. However, both the magnitude of the peatland carbon pool and the development of this pool through time are poorly constrained ${ }^{2}$. In a recently published article, Nichols and Peteet ${ }^{3}$ combine basal radiocarbon dates from palaeoecological studies with previously published datasets of peatland initiation to produce a revised estimate of northern peatland initiation and carbon stocks. The authors conclude that the amount of carbon stored in Northern peatlands is two to three times higher, i.e. $1055 \mathrm{GtC}$, than previous estimates (Gorham 1991; Yu et al., 2010). Nichols and Peteet argue this is due to peatlands initiating and expanding earlier than previously thought, as appears to be the case in the new dataset of peatland initiation they have compiled, of which dates from the palaeoecological literature (Neotoma database ${ }^{4}$ ) form a large component. The approach used by Nichols and Peteet relies on two assumptions 1) That the lateral peatland coverage expands linearly with time and 2) that the oldest basal date in a region is representative of peat initiation in that region. These assumptions have been repeatedly called into question ${ }^{5-9}$ as has the suitability of the Neotoma dataset for basal date information without modern re-processing ${ }^{10}$. We consider peat depth as a means to independently evaluate the $1055 \mathrm{GtC}$ figure, concluding that this would require peatlands to be implausibly deep as compared to peat depth observations ${ }^{11-13}$.

\section{Lack of peat depth and bulk density constraint}

A simple way to check the $1055 \mathrm{GtC}$ figure is to consider whether peatland properties would permit such a large figure. Using the same peatland extent, bulk density and carbon content data $^{14}$ as Nichols and Peteet, peatlands would have to be on average 7.1 meters deep, with 
This is a non-peer reviewed preprint submitted to EarthArXiv, which is now under review at Nature Geoscience.

a possible range of 4.6 to 14.1 meters in order to accommodate 1055 Gt of C (Supplementary information) calculated using the mean and the standard deviation of organic matter bulk density $(n=21220)$ and carbon content $(n=18973)^{14}$. Peat depth in North America has been consistently estimated to be $2-3$ meters ${ }^{11,12}$ and best estimates for Western Siberia is 2.6 meters ${ }^{13}$. International inventories assume a peat depth of 2 meters where detailed inventories are missing ${ }^{15}$. This demonstrates that the peat depth, and hence $\mathrm{C}$ stock estimate of Nichols and Peteet are unrealistic and inconsistant with observed peat depth and physical peat properties.

\section{Linear lateral expansion assumption flawed}

Underpinning the time history approach used by Nichols and Peteet is the assumption that peatlands expand linearly over time from initiation. As such, the peatland area increase over time is proportional to the summed frequency of basal initiation ${ }^{5}$. This assumption has been repeatedly called into question ${ }^{5,6}$ and runs contrary to the overwhelming majority of evidence available from the literature ${ }^{6,16-20}$ spanning a considerable number of peatlands across a diverse range of regions. Importantly, the assumption of linear expansion is untenable as the literature points to non-linear lateral expansion being the rule rather than the exception.

The reason for the restricted lateral expansion is that underlying and surrounding topography will have exerted a strong influence on peatland lateral expansion ${ }^{19,21,22}$. Even a relatively shallow slope $(0.5 \%)$ may halt lateral expansion entirely ${ }^{19}$. After de-glaciation, peat initiation is thought to have begun predominantly in hollows and steep-sided basins ${ }^{9}$. In a practical sense, this often means that peat formation would have remained constrained, with little to no lateral growth for a long period of time. For example, this is seen in a Canadian peatland where peat expansion was confined to basins for 4000 years post-initiation ${ }^{17}$ with similar constraining effects found for peatlands in Finland ${ }^{16}$, Russia ${ }^{22}$ and the United Kingdom ${ }^{18}$. Importantly, neglecting the influence of topography will result in a systematic bias towards the earlier expansion of peatlands. It is notable that in studies that have directly investigated peatland expansion, rather than initiation, lateral expansion is consistently most rapid in the midholocene $e^{6,13,18,23,24}$, even though initiation may have been much earlier. An exception to this is the episodic expansion of peatlands through terrestrialisation of kettle holes ${ }^{25}$.

\section{How Nichols and Peteet differs from earlier time-history approaches}

It is important to note that when the time history approach has been used before, the results have been more comparable to other approaches (e.g. 612 GTC in Yu et al. $2011^{26}$ compared with an inventory-based estimate of 445 GTC in Joosten $2009^{15}$, both estimates of global peatland extent). We argue that it is specifically the combination of the methodology of Nichols 
This is a non-peer reviewed preprint submitted to EarthArXiv, which is now under review at Nature Geoscience.

and Peteet with the Neotoma dataset which makes the new 1055 GT estimate particularly prone to error. Nichols and Peteet gave un-due weight to the oldest date in the region, or grid square, making the approach highly vulnerable to outliers. It has been previously demonstrated that a more conservative requirement of the average of the three oldest dates per region considerably changed the shape of peatland initiation and projected expansion, leading to later initiation and growth ${ }^{5}$.

\section{Problems with Palaeoecological data in combination with the approach taken}

There have been a number of attempts to compile datasets of peatland initiation using published basal dates from the literature ${ }^{8,13,27}$. It is important when dates are being compiled that the supporting stratigraphic context is considered ${ }^{26}$. Palaeoecologists, in particular, are often concerned with getting the longest record possible, rather than dating the initiation of peat per se. As such, it is relatively common for basal dates to be taken in the sediment underlying peat, but it is often unclear whether this has occurred unless the accompanying stratigraphy is also published ${ }^{27}$. Nichols and Peteet make no mention of the quality control criteria used for the Neotoma dates, and indeed it has proved impossible to re-create the exact dataset using the scant information provided. However, in order to provide an indication of the quality of the Neotoma dates, we conducted our own search of the Neotoma database for all records from mires older than 10,000 BP $(n=213)$. We then looked at a random sample of these $(n=20)$. For two original records basal dates were taken from below peat initiation, in glacial gyttja ${ }^{28,29}$, and a further two records had no modern chronological control at all, with primary data sources dating from pre-1940, in these cases the age had been estimated by the original author. It was notable that for the vast majority of records $(n=18)$ we could not obtain adequate stratigraphic information for quality control checking. Therefore, we regard the lack of inclusion criteria and quality control criteria in the methodology of Nicholes and Peteet to be a cause for concern.

Furthermore, outdated calibrations, and the way they are treated, can influence the interpreted initiation dates, with large errors on uncalibrated dates having in the past been misinterpreted as indicative of earlier initiation ${ }^{8}$, this point is particularly relevant given the large errors associated with basal dates from the Neotoma database ${ }^{10}$. Several authors have also highlighted problems with the hard-water effect ${ }^{8,10,13,30}$, which is a valid concern given that peat may initiate at high $\mathrm{pH}(>8)$ conditions after glacial retreat ${ }^{9,31}$. Thus, we again reiterate that the deliberate use of the oldest date for a region, or grid, makes the analysis of Nichols and Peteet highly vulnerable to bias towards older initiation, even with only a handful of erroneous dates.

\section{Moving forward in estimating the global peatland C stock}


This is a non-peer reviewed preprint submitted to EarthArXiv, which is now under review at Nature Geoscience.

Unless realistic models of peatland expansion can be incorporated into estimates of peatland carbon stocks the time-history approach will remain severely flawed. The solution to modelling lateral expansion may lie in using topography surrounding peatlands to estimate topography underneath them, based on digital elevation information in combination with geostatistical and machine-learning approaches. Future carbon stock estimates must make clear the quality control criteria used when compiling dates from the literature. Additionally, we recommend that future model-based approaches for estimating peatland $C$ stock make use of independent measurements of peat depth and carbon accumulation in order to evaluate model performance.

\section{Acknowledgements:}

JLR receved funding from the Kepe foundation and would also like to also acknowledge the late Dr Richard Payne for sharing his insights and ideas regarding the topics discussed in this manuscript.

\section{Data avalibility}

The authors declare that the data supporting the findings of this study are available within the paper and its supplementary information files.

\section{$\underline{\text { References }}$}

1. Frolking, S. \& Roulet, N. T. Holocene radiative forcing impact of northern peatland carbon accumulation and methane emissions. Glob. Chang. Biol. 13, 1079-1088 (2007).

2. Loisel, J. et al. Insights and issues with estimating northern peatland carbon stocks and fluxes since the Last Glacial Maximum. Earth-Science Rev. 165, 59-80 (2017).

3. Nichols, J. E. \& Peteet, D. M. Rapid expansion of northern peatlands and doubled estimate of carbon storage. Nat. Geosci. 12, 917-922 (2019).

4. Williams, J. W. et al. The Neotoma Paleoecology Database, a multiproxy, international, community-curated data resource. Quat. Res. (United States) 89, 156177 (2018).

5. Loisel, J. et al. Insights and issues with estimating northern peatland carbon stocks and fluxes since the Last Glacial Maximum. Earth-Science Rev. 165, 59-80 (2017).

6. Ruppel, M., Väliranta, M., Virtanen, T. \& Korhola, A. Postglacial spatiotemporal peatland initiation and lateral expansion dynamics in North America and northern 
This is a non-peer reviewed preprint submitted to EarthArXiv, which is now under review at Nature Geoscience. Europe. Holocene 23, 1596-1606 (2013).

7. Gorham, E., Lehman, C., Dyke, A., Clymo, D. \& Janssens, J. Long-term carbon sequestration in North American peatlands. Quat. Sci. Rev. 58, 77-82 (2012).

8. Reyes, A. V. \& Cooke, C. A. Northern peatland initiation lagged abrupt increases in deglacial atmospheric CH4. Proc. Natl. Acad. Sci. U. S. A. 108, 4748-4753 (2011).

9. Gorham, E., Lehman, C., Dyke, A., Janssens, J. \& Dyke, L. Temporal and spatial aspects of peatland initiation following deglaciation in North America. Quat. Sci. Rev.

10. Wang, Y., Goring, S. J. \& McGuire, J. L. Bayesian ages for pollen records since the

11. Gorham, E., Lehman, C., Dyke, A., Clymo, D. \& Janssens, J. Long-term carbon sequestration in North American peatlands. Quat. Sci. Rev. 58, 77-82 (2012).

12. Beilman, D. W., Vitt, D. H., Bhatti, J. S. \& Forest, S. Peat carbon stocks in the southern Mackenzie River Basin: Uncertainties revealed in a high-resolution case study. Glob. Chang. Biol. 14, 1221-1232 (2008).

13. Kremenetski, K. . et al. Peatlands of the Western Siberian lowlands: current knowledge on zonation, carbon content and Late Quaternary history. Quat. Sci. Rev. 22, 703-723 (2003).

14. Loisel, J. et al. A database and synthesis of northern peatland soil properties and Holocene carbon and nitrogen accumulation. The Holocene 24, 1028-1042 (2014).

15. Joosten, $\mathrm{H}$. The Global Peatland $\mathrm{CO} 2$ Picture Peatland status and emissions in all countries of the world. Wetl. Int. (2009).

16. Mathijssen, P. J. H. et al. Reconstruction of Holocene carbon dynamics in a large boreal peatland complex, southern Finland. Quat. Sci. Rev. 142, 1-15 (2016).

17. Bauer, I. E., Gignac, L. D. \& Vitt, D. H. Development of a peatland complex in boreal western Canada : lateral site expansion and local variability in vegetation succession and long-term peat accumulation. Can. J. Bot. 81, 833-847 (2003).

18. Tipping, R. Blanket peat in the Scottish Highlands: timing, cause, spread and the myth of environmental determinism. Biodivers. Conserv. 17, 2097-2113 (2007).

19. Almquist-Jacobson, H. \& Foster, D. R. Toward an integrated model for raised-bog 
This is a non-peer reviewed preprint submitted to EarthArXiv, which is now under review at Nature Geoscience. development: Theory and field evidence. Ecology 76, 2503-2516 (1995).

20. Ireland, A. W., Booth, R. K., Hotchkiss, S. C. \& Schmitz, J. E. A comparative study of within-basin and regional peatland development: Implications for peatland carbon dynamics. Quat. Sci. Rev. 61, 85-95 (2013).

21. Loisel, J., Yu, Z., Parsekian, A., Nolan, J. \& Slater, L. Quantifying landscape morphology influence on peatland lateral expansion using ground-penetrating radar (GPR) and peat core analysis. J. Geophys. Res. Biogeosciences 118, 373-384 (2013).

22. Pluchon, N., Hugelius, G., Kuusinen, N. \& Kuhry, P. Recent paludification rates and effects on total ecosystem carbon storage in two boreal peatlands of Northeast European Russia. The Holocene 24, 1126-1136 (2014).

23. Tallis, J. . Growth and degradation of British and Irish blanket mires. Enviromental Rev. Natl. Res. Counc. Canada 6, 81-122 (1998).

24. Weckström, J., Seppä, H. \& Korhola, A. Climatic influence on peatland formation and lateral expansion in sub-arctic Fennoscandia. Boreas 39, 761-769 (2010).

25. Ireland, A. W. \& Booth, R. K. Hydroclimatic variability drives episodic expansion of a floating peat mat in a North American kettlehole basin. Ecology 92, 11-18 (2011).

26. Yu, Z. Holocene carbon flux histories of the world's peatlands: Global carbon-cycle implications. The Holocene 21, 761-774 (2011).

27. Payne, R. J., Ratcliffe, J. L., Andersen, R. \& Flitcroft, C. E. A meta-database of peatland palaeoecology in great Britain. Palaeogeogr. Palaeoclimatol. Palaeoecol. 457, 389-395 (2016).

28. King, J. E. Late Quaternary Vegetational History of Illinois. Ecol. Monogr. 51, 43-62 (1981).

29. Heide, K. Holocene pollen stratigraphy from a lake and small hollow in North-Central Wisconsin, USA. Palynology 8, 3-19 (1984).

30. Macdonald, G. M., Beukens, R. P., Kieser, W. E. \& Kitt, D. H. Comparative radiocarbon dating of terrestrial plant macrofossils and aquatic moss from the ' icefree corridor' of western Canada. Geology 15, 837-840 (1987).

31. Engstrom, D. R., Fritz, S. C., Almendinger, J. E. \& Juggins, S. Chemical and 
This is a non-peer reviewed preprint submitted to EarthArXiv, which is now under review at Nature Geoscience. 161-166 (2000).

195

196 Author contributions

197 J.L.R and H.P concived the study and all authors were involved in writing and revising the 198 manuscript.

\section{Competing interests}

200 The authors declare no competing interests. 